Journal of Southeast Asian

\title{
"Khmer Pride": Being and Becoming Khmer-American in an Urban Migrant Education Program
}

Theresa Ann McGinnis

Hofstra University, theresa.a.mcginnis@hofstra.edu

Follow this and additional works at: https://docs.lib.purdue.edu/jsaaea

Part of the Asian American Studies Commons, Critical and Cultural Studies Commons, and the Education Commons

\section{Recommended Citation}

McGinnis, Theresa Ann (2007) "'Khmer Pride": Being and Becoming Khmer-American in an Urban Migrant Education Program," Journal of Southeast Asian American Education and Advancement. Vol. 2 : Iss. 1, Article 2.

DOI: $10.7771 / 2153-8999.1084$

Available at: https://docs.lib.purdue.edu/jsaaea/vol2/iss1/2

This document has been made available through Purdue e-Pubs, a service of the Purdue University Libraries. Please contact epubs@purdue.edu for additional information.

This is an Open Access journal. This means that it uses a funding model that does not charge readers or their institutions for access. Readers may freely read, download, copy, distribute, print, search, or link to the full texts of articles. This journal is covered under the CC BY-NC-ND license. 


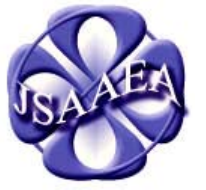

Journa of Ed

Volume 2 l of Southeast Asian American ducation \& Advancement WWw.JSAAEA.org
A peer-reviewed scholarly journal published by the National Association for the Education \& Advancement of Cambodian, Laotian, and Vietnamese Americans (NAFEA)

\title{
“Khmer Pride": Being and Becoming Khmer American in an Urban Migrant Education Program
}

\author{
Theresa McGinnis \\ Hofstra University
}

The Khmer children of migratory agricultural workers were featured in a film ${ }^{1}$ at a Children's film festival. In the film scenes of the students walking through their urban neighborhood were juxtaposed with the "Killing Fields" of Cambodia. Although one can say this representation is a bit extreme, as the new generation of Khmer American youth negotiates the daily complexities of urban American culture, they are constructing their own ways of being out of both their present and their past. However, too often schools reduce the discussion on immigrant youth's identities to a "nativist/assimilationist dyad" (Lowe, 1998). This dyad suggests that there are only two ways of being: assimilating to the ways of the dominant American society, or maintaining Khmer culture and traditions. Lowe (1998) asserts that this discussion obscures the particularities that complicate and diversify these youth's experiences. The complexities of the Khmer youth's identities and experiences are investigated in this article.

The families of these Khmer youth share historical, political, and economic situations as a result of their migration to America in the face of horrors and losses suffered at the hands of others. Many of the families have lived through the terror of the Khmer Rouge and the Vietnamese invasion. They have lived in refugee camps and have now resettled in a foreign country. As agricultural workers in the United States, their more recent migratory movements have brought them from rural poverty to impoverished inner city neighborhoods. In this article, I explore these historical circumstances, issues of cultural survival, concerns around assimilation and peer pressure. I provide a look into the idea that identity is not a fixed entity and is instead worked out or constructed both "horizontally" within communities and contexts, as well as "vertically" transmitted from one generation to another (Lowe, 1998). Further, I address how identity cannot be separated from what is peculiar to these youths' lives: poverty, family stories, cultural attributes, gender and peer culture.

Additionally, in this article I focus on an urban Migrant Education Program that was developed to serve the needs of Khmer families living in the greater Philadelphia area. I share how the Migrant Education Program (MEP) becomes a space where the children of these families can explore who they are as Khmer youth living in an urban American context. I discuss how these youth are able to take a transformative, interactional stance to their literacy and sign-making practices within the urban Migrant

\section{(ब)}

SOMERIIGHISRESEREEDReaders are free to copy, display, and distribute this article, as long as the work is attributed to the author(s) and the Journal of Southeast Asian American Education \& Advancement, it is distributed for non-commercial purposes only, and no alteration or transformation is made in the work. More details of this Creative Commons license are available at http://creativecommons.org/licenses/by-ncnd/2.5/. All other uses must be approved by the author(s) or JSAAEA. 
Education Program. Thus, I argue that these Khmer youth's identities are reflected within these literacy and expressive practices, as "partly inherited, partly modified, as well as partly reinvented” (Lowe, 1998, p. 65). The experiences of these Khmer middle school children of agricultural workers provide rich examples of how immigrant youth draw on a variety of cultural resources (from urban American culture and from their own Khmer cultural inheritance) in constructing layered identities.

\section{Research Design, Setting, and Participants}

The data presented in this article are part of a five-year (1997 - 2002) longitudinal ethnographic research project that explored the intersection of identity, literacy, and discourse practices within the urban public middle schools, a Migrant Education Program and the communities of Khmer-American youth. I adopted the ethnographic approaches of the New Literacy Studies that examine language and literacy as aspects of and embedded within social practices (Barton 1994; Gee 1990; Street 1995). These ethnographic methods provided the tools to record the complexities of the situational and interrelation aspects of identities and literacy practices within and across contexts (Marshall \& Rossman, 1995). In order to get an in-depth picture of the complex relationship among literacy, discourse practices, and identity, I combined several data collection methods over the course of this study: participant observation, personal communications, photography, and review of archival materials. Data sources were coded and categorized based on the research questions, the theoretical framework, and grounded theory approaches.

The Khmer youth and their families live in the greater Philadelphia area where the parents, and sometimes the youth, are bused to regional farms to pick fruit. Most of the families are among the third or even fourth waves of refugees, arriving after 1980 through the mid 1990s. The refugees in these waves were among the poorest and least educated. The migrant education families come from farming backgrounds and had little to no education. Upon their arrival, according to Toan, a migrant education coordinator and Cambodian refugee, "the first thing they focus on is working in fields, like picking berries, fruit, apples, stuff like that” (personal communication, February 24, 1999). Many families have moved several times in search for work and lower cost housing since they have been in the United States.

The Migrant Education Program (MEP) is federally funded and provides supplemental education for children of migratory agricultural workers on Saturdays, after school, and during the summer. The general goal of the MEP is to help children of migratory agricultural workers experience success by diminishing the effects of the interruption of education experienced because of the frequent movement of families. The objectives set by the coordinators of this urban program centered on building school skills, but also providing students with a safe place. The Khmer language teacher was interested in maintaining the Khmer culture of the students. The younger staff members, primarily former MEP students, felt it was a place to build self-esteem and friendships.

To qualify for the Migrant Education Program, the students' families must work in agriculture or in poultry plants, and the students must have moved with their families across school district boundaries in the previous three years. Of the students who attended the program in this urban setting, the majority were Cambodian (ethnic Khmer). 
Although each student was of course unique, all of them considered themselves ethnic Khmer. The Khmer students attend public schools throughout this northeastern United States city during the school year. In some schools, a student from the Migrant Education Program might be the only Cambodian student in the class; in other schools, up to 20 percent of the student population was Cambodian. Students who did not live within walking distance were bused to the Migrant Education Program. The program provided classes in art, science, English literacy, martial arts, and cultural dancing, as well as in Khmer, Vietnamese, and Chinese. I worked at the MEP from 1996 - 2001 as the English Literacy teacher.

I came to know each of the student participants in this project through my work as a teacher with the Migrant Education Program. There were approximately twenty middle school aged Khmer American youth who attended the program at the beginning of my research. From this core group of students I narrowed my focus to five young people. As the families of the students moved in and out of the area I focused on other students and hence, my total of key participants became eight. Of those eight participants, five were young men and two were young women.

Throughout the duration of this research I played multiple roles. As a teacher for the MEP, I taught all grade levels on Saturdays and during the summer program. Thus, I was thought of by students as Miss Terry, their teacher. As a participant/observer, I took fieldnotes, conducted personal communications, and collected artifacts from some of my middle school students at the MEP and at their public schools. My observations within the MEP occurred over the five-year period on Saturdays, after-school, and during the summer. I observed in the public school settings at two K-8 schools and one middle school twice a week during the 1998/1999 school year. I conducted one formal interview with each participant and several informal interviews over the course of the five-year study. In addition, I developed relationships outside of these two settings and interacted with the students in their community and in their homes. Most often, however, they and their families viewed me as a teacher.

Because teachers are highly respected in Cambodia, and because I live in the community of my students and make home visits, my role as teacher provided me with access to families that I may not have had as a purely white academic researcher. The nature of the MEP also allowed me to develop relationships with the students, which I would not have had the opportunity to do as a public school teacher. At the MEP, I ate lunch daily with students and spent time with them in less structured settings like roller rinks and swimming pools. Although my rapport with the students and their families was good and comfortable, as a white female teacher, I was not considered a peer, and definitely not Khmer, therefore I am aware there were limitations to my research, and that the Khmer youth may not have discussed certain issues with me. Like the other teachers in the program, I was a certified public school teacher. In addition to the certified teachers, the Migrant Education Program was committed to hiring former students as teaching assistants and staff. Several of my former students became teaching assistants in the program.

The Khmer youth in the study were too young to have been born during the reign of the Khmer Rouge or the Vietnamese invasion of Cambodia. However their life narratives are shaped by their families' history of the genocide under the Pol Pot regime, the Vietnamese invasion, famine, flight, long stays in refugee camps, and relocation in a 
foreign country, followed by secondary migration within the United States after their arrival. The youth's individual identities and social realities were shaped by four dimensions reflective of this history and cultural background: distinct linguistic, cultural, and historical characteristics; survival skills and psychologies related to war, adjustments to a new country as refugees, and discrimination, disenfranchisement, and racism due to their economic and political status in their new country (Kiang, 1996). In addition, as will be discussed in the following sections, the students in the Migrant Education Program faced racism in their schools, peer pressure, and the effects of urban poverty.

\section{Theoretical Framework}

Theoretical frameworks that rely on poststructuralist approaches to the study of literacy, identity and culture (Gee, 1999; Martin-Jones \& Jones, 2000; McCarthey \& Moje, 2002; Street, 2000) foreground the influences of literacy ideologies and power structures on the options, opportunities, and access provided to immigrant youth in educational settings. Such work examines the ways literacy practices are situated in social, cultural, political and economic contexts, as well as the role these literacy practices play in identity construction. Also, the investigation of local and community-based literacy practices (Barton \& Hamilton, 1998; Heath, 1983) have been useful in looking at the language and literacy socialization of immigrant youth in various contexts.

In addition, recent views of identity recognize that youth construct themselves in terms of multiple social identities that are negotiated in relation to literacies, histories, circumstances of discourses of power, and desires (Hall, 1997; Gee, 1990). Identity is not seen simply as a process of being, but also as a process of becoming (Hall, 1997). Identities are dependent upon social relations and material conditions (Bakhtin, 1981; Holland, Lachicotte, Skinner \& Cain, 1998). As Holland et al. (1998) states "identities are improvised - in the flow of activity within specific social situations-from cultural resources at hand" (p. 4). In other words, how one sees oneself and is acknowledged by others is enabled and/or constrained by the available cultural resources and their social relations. Yet, there are possibilities for personal agency. It is possible for identities to be constructed in response to or in resistance to cultural and social relations.

Working within a sociocultural perspective of literacy (Barton, 1994; Gee, 1990; Street, 1995), and poststructuralist notions of identity (Gee, 1990; Hall 1997; Holland, Lachicotte, Skinner \& Cain, 1998), I explore the intersections of the Khmer youths' literacies, identities and cultures. These practices, through which their identities are enacted, illustrate the complex ways that youth's identities and multimodal expressions are reflective of their daily realities. In this article, I investigate the multiple and complicated ways the youth's identities are constructed, negotiated, and performed within specific contexts and literacy practices. Additionally, I look at how the Khmer youth read, write, and interact around a range of semiotic sign systems in particular settings. I consider how the Khmer youth use reading and writing in combination with other semiotic modes, such as art, dance, the martial arts, and clothing, to create multimodal forms of expression (Kress, 1997). I discuss how the choices of materials and modes of the Khmer youth are culturally, socially and economically shaped (Kress, 1997, 2000). Therefore, their meaning-making processes draw from social and cultural contexts in which they are positioned as producers of texts in relation to existing semiotic systems 
(Hodge \& Kress, 1988). I examine how the texts the Khmer youth produce are formed within their material conditions, and take on particular meanings within the socially and culturally specific environments at a particular moment in history (Bakhtin, 1981; Holland et al., 1998; Kress \& van Leeuwen, 2001).

\section{Cambodian Refugees in the United States}

As waves of Southeast Asian refugees were produced by various political upheavals, war and persecution, many found themselves beginning a process of unplanned and rapid adjustment to a new life in the United States. In particular, Cambodian refugees were people who had fled their country, endured life in refugee camps, and resettled in a new country - the United States (Ledgerwood, Ebihara \& Mortland, 1994). Hein (2006) asserts that this process of resocialization not only involves the refugee's history, politics and culture of their homeland, but also involves coping with new identities and inequalities following migration. Cambodian refugees and immigrants come to the United States with "interpretive frameworks of how they make sense of the world around them” (Smith, 1994).

As noted earlier, the history of the Cambodian refugees includes the Khmer genocide under the Pol Pot regime. This traumatic experience continues to cause postmigration stress within the Cambodian community (Nou, 2006). Socioeconomic deprivations are another aspect affecting Cambodian refugees in the United Sates (Chan, 2004; Hein, 2006; Nou, 2006; Ong, 2003). Both Hein (2006) and Chan (2004) point to low levels of "human capital" upon arrival of the Cambodian refugees; that is, they did not have high levels of education, transferable job skills, or knowledge of United States culture (Chan, 2004; Hein, 2006). Ong (2003) further elaborates and explains that as exploited Asian workers, like migrant agricultural workers, there is little room for improving one's socioeconomic status within the United States' neoliberal market economy. The homeland religion, Khmer Theravada Buddhism, also plays a significant role in the lives of Cambodian refugees (Hein, 2006; Ong, 2003; Smith-Hefner, 1999). Thus, Khmer notions of personhood such as virtue, meritorious acts, and communalism, can at times be at odds with American values such as independence and self promotion, which the Cambodian refugees are expected to adopt (Ong, 2003; Smith-Hefner, 1999). Finally, as refugees, the Cambodian people are trying to retain and reclaim their Khmer cultural practices. They are trying to fit their cultural practices into the new contexts of their new country (Ledgerwood et al., 1994).

As part of their adjustment to their new country, the children of the Cambodian refugees find themselves negotiating complex United States communities, public schools, and cultural practices. As Khmer youth they have experienced the stressors of their parents, including cultural adjustments and socioeconomic deprivations. In particular, the Khmer youth are cultivating multiple identities which include the negotiation of class, race, religion, ethnicity, and gender (Levitt \& Waters, 2002; Suarez-Orozco \& QinHillard, 2004). This process can at times present contradictions and challenges for these youth, whether in school, or within their communities. The Khmer youth's multimodal expressive and communicative acts afford a space for cultivating these multiple identities (Reyes, 2007). These will be discussed further within the following sections. 


\section{“The Hardest Thing is that We are Different"}

Suarez-Orozco \& Suarez-Orozco (2001) point out that the varied socioeconomic and educational backgrounds of immigrant families influence a child's opportunities and experiences in different ways. They state "parents of more limited resources will tend to gravitate to poorer neighborhoods where they are likely to find inferior schools” (p. 128). In addition, they add that urban neighborhoods with the most affordable housing are often located in highly segregated neighborhoods. This affects the kinds of English dialects youth are exposed to, their access to jobs, and exposes them to the influence of youth gangs. Indeed the families in this study live in such poverty stricken neighborhoods, and their children attend urban schools that had been labeled as "failing" by state officials. Thus, the Khmer youth have adopted the "style" of urban youth culture. Their clothing, hair styles, speech and behavior reflect an urban youth social network (Gee, 1999). As Lee (2005) discusses in her work with Hmong students, these Khmer youth are also viewed by others as poor, urban, immigrant or refugee youth-as "non-white" and as "non-model minorities."

The view of youth as "non-model minorities" positions them inside schools as burdens or challenges. This positioning also leads to narrow school curricula that is meant to improve these poor, urban immigrant youth's academic abilities as measured by test scores (McGinnis, 2007). Within this skills based school curricula there is little room for the youth to engage in literacy practices that allow for creativity, or for them to explore their situations as Khmer youth living in urban America. Thus, teachers receive a narrow view of their students, their abilities and their cultural values. For example, an eighth grade teacher, an African-American woman remarks, "these students with the refugee background for some reason have adopted the street demeanor, and other students complain that they are threatening them.” She continues to explain, "They have this beautiful culture, but the kids don't want anything to do with it. These students seem like Blacks, their features, their skin color, so much about them. They want to be Black.” This teacher's comments ring true for her based on her own experiences and her interactions with the Khmer students. Her assumptions are based on the image these students project at school, yet, these images are not all there is to these youth. While there is no simple, static form of identity that develops among them, there is, at the same time, a collective "Khmerness" or subculture of what it means to be Cambodian in an urban context. Their individual identities and collective shared identities are a complex entanglement of different layers (Jenkins, 1996). Sometimes, as in the case of this teacher, it is only the surface layer, or the identity markers that these students wish to project or are able to project within certain educational spaces, that are visible to others.

What this teacher does not see at school are the students' shared Khmer values and beliefs. Beneath the image appropriated from the youth around them, lies their knowledge that they are different. Many wear strings decorated with long shaped tube beads beneath the outer baggy T-Shirts, tied around their waists. When I asked Vantha ${ }^{2}$ about his strings, he told me, "my dad gave it to me to help get rid of my bad dreams." The other boys standing around said they are called dreambelts. Than remarked, "Mine is a belt to ward off evil spirits." He explained further, "When my uncle was sick the American doctors couldn't figure out what was wrong, but the Buddhist doctor that come out from Seattle figured out what was wrong. He cured him. I got the belt from the 
Buddhist doctor.” These youth maintain spiritual traditions or folk beliefs that have been passed down though oral traditions from grandparents and parents. These beliefs and values contribute to their Khmer identities. These youth know they are not AfricanAmerican. They are Khmer. Although they are proud of their Khmerness, it is also part of their struggle to fit in. One boy, now 19 years old, said, reflecting back on his school and gang experiences, "The hardest thing is that we are different."

The students do seek out others that are similar to them. As we passed an abandoned building on our way home from a Migrant Education fieldtrip, a student asked the question, "Why can't we make our own school for Cambodians?” The importance of creating caring and supportive learning communities that address the cultural and emotional needs of students has been discussed by several researchers (Collier, 1995; Igoa, 1995; Lee, 2005; Suarez-Orozco \& Suarez-Orozco, 2001; Valenzuela, 1999). Many educators argue that valuing the students' experiences with language, literacy, and culture will help to create culturally sensitive communities of learning (Diaz \& Flores, 2001; Perez \& Norlander, 2004; Valenzuela, 1999).

The Migrant Education Program has created a culturally sensitive community of learning. Also, because the majority of students are Cambodian, it is a place where the students can be with friends who are also Khmer. Thus, the Migrant Education Program serves as a Khmer community for these students. In addition, within the Migrant Education Program the Khmer youth are allowed the time and space to engage in cultural productions. Through the examination of their cultural productions, particularly multimodal textual practices, I discuss in the sections that follow how the Khmer youth were able to engage in important identity work. As will be shown, these youth engage in youth cultural practices of urban America, the cultural practices that are a part of a larger global youth culture, and they experience the cultural practices of the Khmer people who are trying to rebuild their culture in a new world.

\section{The Apsara}

Mr. Keo, the Khmer language teacher for the Migrant Education Program, remarked that "Culture is the soul of each nation. Elimination of culture is an elimination of the nation" (personal communication, April 3, 1999). Indeed, during the Khmer Rouge period many of the cultural artifacts, arts, and social ideals of Khmer society were destroyed. Artists and intellectuals were slaughtered by Pol Pot, leaving behind a shortage of teachers and performers (Sam, 1994). Many Khmer adults believe that in losing Khmer cultural traditions, what it means to be Khmer will also be lost. Maintaining their cultural resources and reestablishing Khmer traditional ideals, therefore, plays an important role in Khmer communities across the United States (Ledgerwood, 1990). The Khmer community in the greater Philadelphia area shares these sentiments. With the youth being exposed to and choosing urban American values, music, dance and ways of being, Khmer parents, religious figures, and community elders fear that the youth will not learn the Khmer traditions nor continue to pass them on to future generations. Because they fear the loss of culture and traditions, they have attempted to impress upon the youth the importance of maintaining specific cultural practices. 
Traditional dance has been cited as a way for Khmer communities to restore their cultural traditions. The Apsara dance is used by Khmer in America to retain the importance attached to their original identification as "truly Khmer" (Ledgerwood et al., 1994). According to Ledgerwood (1990), embedded in the Apsara dance are Khmer notions of women which include adjectives such as: kind, gentle, graceful and refined. Khmer feminine comportment, speaking softly and moving slowly, are also symbolically represented through the Apsaras, celestial dancers, whose figures decorate Angkorean temples (Catlin, 1990). In addition, the Apsara dance is viewed as an intrinsic bond between the Khmer past and the present (Catlin, 1990).

Sadly, the migrant education dance teacher, a young college student, was shot and killed in a neighborhood Khmer video store. Her death raised many fears among this Cambodian community about the safety of their neighborhood. In addition, her death raised concerns about the transmission of the traditional dances, a symbol of Khmer culture, to the younger generation. Though the girls in the Migrant Education Program may not know the exact historical connections, they do recognize the cultural symbolic nature of the Cambodian traditional dances. For the teenage girls of the Migrant Education Program, there are mixed feelings about performing traditional dances. Some perform them because they are forced to by teachers, others perform because they want to wear the bright colored costumes, and others simply enjoy dancing (personal communications, 7/00, 8/02). For all of the girls I talked to, regardless of their feelings about performing, they recognized Cambodian traditional dances as representative of their Cambodian heritage. That is, for them dance signifies a knowledge of their cultural inheritance. For example, Chandra remarked, "Dance is the beautiful part of our culture" (personal communication, July 20, 1998). On another occasion, during a trip to the local museum we viewed a preserved Indian Temple. The influence that Indian culture had on Cambodian traditions became apparent when one of the teenage dance performers came to me and pointed to one of the Goddesses supporting the temple ceiling. While she was pointing at the Goddess she explained, "That is how Loung and I will look when we perform on Saturday" (personal communication, July 23, 1998). Here I look specifically at the Apsara dance as a site where the multilayered vertical and horizontal aspects of these Khmer youth's identity are constructed.

The Apsara dance, a dance known for its complicated movements and its length, was one the teenage girls were learning in the Migrant Education Program. They planned to perform it at an annual festival sponsored by the Migrant Education Program where they would perform for students and their families from other Migrant Education Programs across Pennsylvania. In preparation for their performance of the Apsara, the girls were concerned with the details of the movements and hoped to avoid embarrassment in front of the audience. The week before the performance, their anxiety built and they skipped classes to rehearse in the unairconditioned auditorium of the school that hosts the Migrant Education Program.

The day of the event they woke up at 4 a.m. and met at Loung's apartment. Loung was a newly graduated high school student who had taken over the role of dance teacher. They got dressed in their rented costumes, fixed their hair, applied their makeup and added long fingernails. At the event, while the younger children gathered around the outdoor stage, nervous chatter echoed throughout the group of teenage girls who would soon be performing the Apsara. Anxiously, they applied the finishing touches to their 
makeup, added gold bracelets to their already ornate costumes and marked the dance movements for the last time. As they quietly walked out and found their places on the stage, their demeanor, posture and carriage changed.

The music began. A Khmer woman sang the narration of the dance in a high shrill voice. The girls' movements followed the subtleties of the music. They engaged in slow, methodical placements of their feet balancing as they moved from one position to the other. Their hands were the important focal point of the dance as with fluid movements they emphasized the flexibility of their wrists. Dressed in gold crowns and ornaments, they looked like the goddesses come to life. They created the images of the dance, elegant, heavenly, Apsaras. For this instance they were Khmer women, graceful and refined and yet they are that and much more. They are connected to the Khmer cultural line that spans years, continents and generations.

At the end of the dance the girls ran off the stage. They removed their long orange and gold skirts and replaced them with their preferred attire of very small shorts. They removed their head pieces, and put their platform shoes back on their bare feet. Some of the girls remained in their spandex silver lamé shirts; others changed into tight fitting tank tops. Most of them left their arm bracelets, ankle bracelets and makeup in place. Although they left some of the costume pieces in place, they removed the major pieces and replaced them with their urban youth attire, it might have seemed as if they were stripping away the traditional Cambodian appearance and replacing it with their more contemporary look. They take a part of Angkor with them, however-the gold jewelrya symbol of their Khmerness, and a part of their connection to grandmothers and mothers.

When all the performances were over, the stage turned into a dance floor. Rap music began to play. The once serious and reserved girls began wildly dancing without restraint and precision. Even the girls whose parents do not allow them to interact with boys did not hold back with any of their dance moves. They danced in a group moving their shoulders and hips simultaneously back and forth to the beat. The boys jumped in and became sandwiched between the girls. Together they shook their bodies closer to the floor and up again laughing as they mouthed the words of the song. They continued dancing in this urban American style that contrasted sharply to their classical Khmer ballet.

These girls are "many different and contradictory things simultaneously, different aspects of [their] character can be emphasized" (Ledgerwood, 1990, pg.317). The Apsara and hip hop are stylistically different, one is a slow and precise dance, and the other is an unrestrained and informal dance style. In one context, the girls emphasize their Khmer female attributes and later emphasize their urban American attributes. The migrant education festival becomes a site of production of the two aspects of these Khmer adolescents' feminine daily identities. At the event both axes, vertical and horizontal, exist (Lowe, 1998). Through negotiation and appropriation these girls are in a complex, dynamic process of becoming Khmer-American women. Though at times this process can result in a clash between Khmer ideas of women as graceful, soft and fluid, and urban American ideas of women as individual, vocal and independent, within the Migrant Education Program and in their daily lives the two axes of their cultural inheritance cannot be separated but instead they work together. Thus, there becomes a possibility of both as part of the girls’ feminine identities. 


\section{Language as a Symbol of Culture}

Like traditional dance, language can serve as a powerful symbol of cultural identity. The Khmer youth in the Migrant Education Program told me that, for them, the Khmer language is a primary marker of their "Khmerness." They knew that someone was Khmer if that person spoke Khmer. For example, one girl whose father is ethnic Chinese, but whose mother is ethnic Khmer told me, "When I first came here they (the Khmer kids) thought I was Chinese. They used to tease me and say things to me. Once they learned that I spoke Khmer and was from Cambodia, I was accepted” (personal communication, July 20, 1999). Other youth told me they didn't think one boy was Khmer at first, because, "We never hear him speak Khmer” (personal communication, July 28, 1999).

Mr. Keo, the Khmer language teacher, made it clear. "Our language is not Cambodian as many Americans call it, but is it Khmer. We are Khmer." Allowing students to explore and identify with their native language and culture is important for their cultural identity (Nieto, 1996). The MEP validated the cultural identities of its students and supported development and use of their heritage language, affording students the opportunities to express themselves freely in their first language and to learn about its writing system (McGinnis, 2005).

The Khmer language is also important, because it is tied to other cultural symbols like dance and food (Needham, 1996). When there was a discussion about encouraging students to use English during the summer program, Loung responded, "We have to use Khmer in the cultural dance. It is a part of the dance and in the music" (Fieldnotes, 6/30/98). During lunch when I asked students about the pickled grapes they were eating with a mixture of salt and sugar, one girl explained to me how her mom pickled the fruit in a big tub in the backyard. As she was explaining the ingredients for the mixture of salt she came to an ingredient that she only knew in Khmer. She said, "I don't know the English word for that" (Fieldnotes, 8/9/99). There were several other times when students talked about food where they did not know the name in English.

The Khmer language class not only serves to support the students' use of their Khmer language, but also to teach them about the culture and history of Cambodia. Passing on culture and history to the young people, already an important value in Cambodian society, becomes particularly vital to a community that has relocated to a new environment. The young are seen as an important means of keeping Khmer culture and history alive. In addition, learning about Khmer culture and history enables the Khmer youth to explore and identify with their cultural inheritance. In the Migrant Education Program, the youth received books on Angkor Wat; the books pictured the gods that watch over the temple, giving their names in Khmer. Mr. Keo also had the youth write in English about the Cambodian government, the Khmer Rouge period, and the national symbols of Cambodia such as Angkor Wat and the Cambodian flag.

The Migrant Education Program creates educational practices and environments that support Khmer language and literacy use in dynamic ways; the use changes naturally according to the purpose and contexts. Through this support of Khmer language and cultural practices, the Migrant Education Program provides a critical space for the youth to explore their Khmer identities. 


\section{The Discourses of Gangs}

These youth are involved in a complex Cambodian culture that intertwines with American urban social and cultural aspects. The forces of peer pressure, gang affiliation and the presentation of tough outer images of the young adolescent boys are part of their multilayered identities. As adolescents living in an urban context, part of the world or environment of these Khmer youth involves the urban subculture of gangs. In representing this aspect of their world, some of these Khmer youth have adopted the "discourses" of gangs. This "Discourse" involves intricate visual signs that are a systematic means for making meaning. Meanings are carried through the ways which they dress, act, talk, gesture, and write (Gee, 1999). As makers of particular signs they are displaying their knowledge of and/or membership in a gang.

The Migrant Education Program has youth explore these symbolic meanings. The program coordinators position the youth as "at risk" of joining gangs, but also position them as experts on gang-related issues. Thus, the Migrant Education Program creates a space for dialogue around gangs. Seteya who was on the fringe of gangs in his neighborhood was viewed as an expert and asked to share with other students about the negative aspects of joining gangs. This was a way to engage him in after-school work and also to get him involved in something that interested him. He created a presentation for the other youth. His presentation included the ways in which one demonstrates a gang identity. Setaya explains, "A gang member is someone who wears a certain style of clothing, uses non-verbal hand signals and uses nick-names" (Fieldnotes, 10/3/00). After his presentation, Setaya noted, "It went well. I got a chance to teach other people what I did - what not to do" (personal communication, October 3, 2000).

These statements do not only pertain to formal gang members, however, but also to the other Khmer youth who live in this urban context. These boys have chosen clothing, markings on their clothing, a demeanor, stance and hair styles that represent an image. These symbolic forms of identity or "Discourses" (Gee, 1999) send out messages to others about their identities. Even if they do not officially belong to gangs, these boys, some eleven years old and younger, hang out in groups, wear baggy clothing and baseball caps with their nicknames written in gang lettering inside the rim and perform non-verbal hand signals. In this case, when simply looking at the surface level of the boys' choices of clothing, one may read the message as, "I am a tough urban street youth," or "I have gang affiliation." They are on the fringes of gangs, which put them into danger of being included in gang activity which Seteya notes, is "criminal activity." The Migrant Education Program extended itself into finding different avenues for discussion about the reasons youth join gangs, and getting them to think about alternatives to gangs.

During free writing assignments students were allowed to write memoirs of youth they knew who had died in gang related incidents. One boy wrote about a cousin he lost in a gang shooting. He titled his writing, "In memory of crow" [sic]. Another project involved a group of middle school girls who chose to write about gangs for a small inquiry project they designed. They wanted to write an article for the summer Migrant Education Program newsletter. In their article they decided to tell the younger students why gangs are "bad to join." In their writing piece they discussed a shooting that took place in their neighborhood two years prior which had devastated the community. Several Khmer boys were injured in the shooting, and two boys died. The girls wrote that since 
the shooting, "There hasn't been as much fighting." They want the youth to "think first," before joining a gang, and to learn from the past histories of those who were in gangs.

These types of literacy practices that allow youth to express their feelings about real events and to inquire into the cultural practices of their neighborhoods are important aspects of the migrant education curriculum. This type of literacy curriculum provides young adolescents, like these Khmer youth, a space for self-expression and identity work in ways where they can see the relevance of literacy to their own lives. When they are allowed to consider social factors that impact their daily lives, they are being empowered to learn about who they are as Khmer American students in an urban community.

\section{Martial Arts}

The martial arts class within the Migrant Education Program is also a place for the young adolescent boys to explore their "tough guy" or "cool guy" images. As Setaya points out, “All my friends do it [martial arts]" (personal communication, July 27, 1998). They learn the techniques and protocol of the traditional martial arts in the classroom, and also get to practice the movements they learn from older brothers and uncles in their community. In addition to learning about the martial arts, the Khmer youth perform the martial arts for the migrant education community. These performances are highly choreographed and put to the music found by one of the Khmer high school students-a popular Japanese disco song. I describe a performance here to provide a sense of the Khmer youth's style of martial arts.

Adorned in borrowed karate and kick boxing clothing, the Khmer youth perform their stunts to the audience of the students and staff of the Migrant Education Program. The music came on loud and fast. The boys came out two at a time and fought with each other. They jumped and spun, spun and kicked, got pushed, got flipped over, fell into somersaults or rolled. Two boys fought with long sticks. Another boy twirled two sickles. At one point, three boys, Vantha, Prussia, and Ratana were fighting. Their weapons consisted of a fan, a gourd and a stick. Vantha demonstrated his composure during the fight by taking a few seconds to bite into an orange after a somersault. The music crescendos as the exhibitions got faster and faster. In the finale, each boy came out, did a move and then bowed (Fieldnotes, 7/2/99).

While many of the martial arts moves, as noted earlier, have been passed down from the men in their families and community, their performances reflect many of the video games they play, and also the fighting scenes in many of the Chinese movies they watch that have been dubbed into Khmer. They also have nicknamed one boy "Jet" after Jet Lee, a martial arts actor who is known for his speed. Therefore, the youth are creatively appropriating different martial art moves, music and styles. They are producing cultural forms that involve the creation and modification of forms they have appropriated from their own experiences with their world. The Migrant Education Program allows them this space within the martial arts program.

\section{Video Games and Japanese Comic Books}

In addition to Khmer cultural practices and urban youth culture, the students' world is saturated with popular youth culture. Through the globalization of markets this youth 
culture is influenced by diverse cultural forms and new technologies. These multimodal textual practices are also reflective of the Khmer youth's continuing dialogic of identity formation. Because the curriculum of the Migrant Education Program centers on the students' interests and allows for choice in many literacy projects, the Khmer youth are able to integrate video games and Japanese anime culture into their textual productions.

For example, Prussia told me that he spends many hours playing video games. He said, "The job that I want to do in the whole world is a video game maker because I want to make decent games that people would like to play." His life goal is to become a video game maker. He has begun to fulfill his desire. For a class project in the Migrant Education Program where the youth were creating collages about their interests, he created his own pop-up video game character. Using only pencil on white paper, Prussia drew his character. Prussia selected for the features of his character items from his own life experiences. The character has large eyes similar to Japanese anime characters. The physique of Prussia's character is not exaggerated, however; instead it is more realistic. He has created his character right down to the details of the clothes the character is wearing. These are similar to the clothing choices of an urban Khmer youth, a FUBU brand tee shirt. This brand, For Us By Us, was created by urban American youth as an affront to Tommy Hilfiger, a popular designer for youth. Prussia's video character is also wearing a baseball cap tilted sideways, and a necklace-a peace sign. The character is dressed much the way that Prussia dresses. The cutting out of his character and the displaying of it in a pop-up fashion transformed the character from a flat representation to a physical concrete object, thus giving the character a potential for action (Kress, 1997). Prussia's creation of a pop-up character also strengthened the importance and significance of his character.

Prussia's production of his video game character was not the mere copying of an already existing video game character, but was a creative transformation of the video game characters he has experienced. Through his use of idiosyncratic features, this act is an expression of Prussia's interest and is reflective of the cultural resources he has available to him. Prussia's daily life experiences include a multi-layering of cultural symbols and markers which are expressed in this multimodal text. He has pulled his choices of design from his experiences of living in an urban context, and from his interaction with new technologies to create a multi-layered representation of his world.

For Vantha, it is comic books that are his passion. During the program's silent reading time, his choice of reading was comic books he had purchased himself with money he had made helping his father on the weekends landscaping. Vantha does not simply read his comic books; he interacts with them in a transformative way. While he looks at the books, he draws in his sketch book He told me, "I draw pictures as I read the comic books. I use them for ideas for my own creations” (personal conversation, July 8, 1999).

Vantha is taking a productive stance to the comic books. He recognizes the qualitative subtleties of the images, analyzing the aesthetic values of the picture, noticing the details, the style of the artist and the shading of the images. In this way he is interacting with the text and producing new visual texts in relation to the existing semiotic symbols of the comic book.

Vantha recognizes that an image can carry a message or convey meaning. For

example, he had drawn a picture of a dragon which held a cultural resonance. For Vantha, 
the dragon represented the Khmer belief of an animal of the gods, a very powerful and wise creature that can see into the future (personal communication, July 15, 1999). For the Khmer youth, the dragon also acts as a protector. Vantha is very aware that his dragon represents different ideas from the Western fire-breathing dragons. His belief is rooted in Khmer traditional values, and represented in the image of the dragon. Thus, the image contributes to his Khmer group identity. Yet, as a character for his own comic book, the dragon connects him to a popular global youth culture of Japanese anime.

\section{“Khmer Pride”}

In the Migrant Education Program the students display their shared "Khmerness" through the words "Khmer Pride" or the letters KP. These words show up, sometimes in large bubble letters or in Graffiti art, on Khmer language class folders, reading folders, ESOL journals, assessment portfolios, chalkboards and tee shirts. Prussia wore a T-shirt on which he had written the words "Khmer Pride" and had drawn the image of his video game character. More recently there are websites on the internet where youth discuss their "Khmer Pride." For example one boy wrote, "putting both of my hand high to the sky saying 'Khmer Pride.' Thus, through newer technologies Khmer youth in the greater Philadelphia area can build a virtual Khmer community with other Khmer youth living around the country.

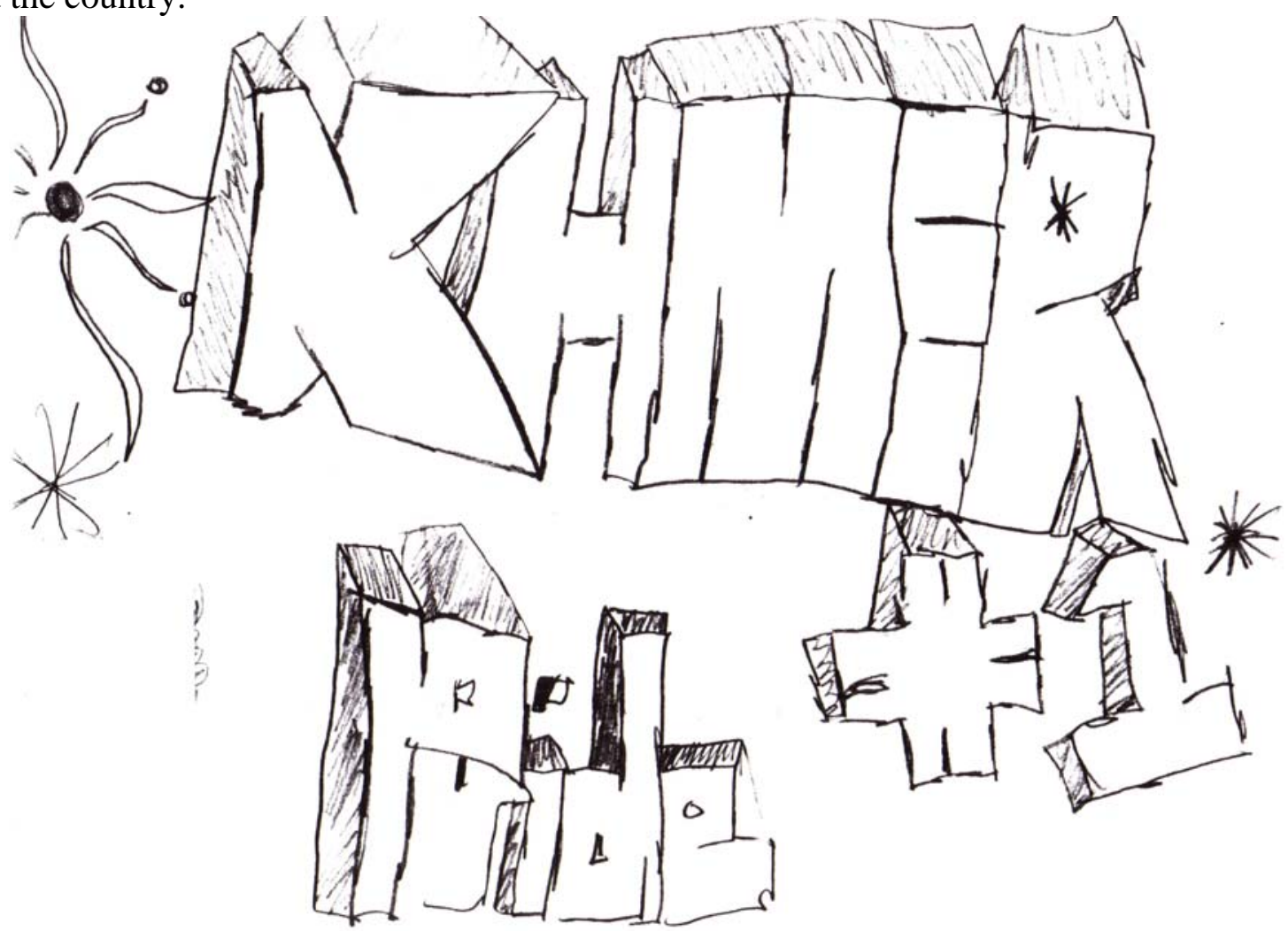

The marking of items with the words "Khmer Pride" is a very obvious way that these youth communicate their Khmer group identity - their solidarity. Yet, in examining this one multimodal textual production, multiple layers are discovered. The style of lettering itself is a sign, or mode (Kress, 1997). Block lettering similar to some of the 
urban gang affiliated writing and the word pride is a representation of the knowledge of the rap lyrics discussing "gangsta pride," or one neighborhood gang "Original Khmer Pride.” Thus, the sign also marks the youth's connection to, or member of, urban youth culture.

The word 'pride' also expresses solidarity for a particular group of individuals, such as "Gay Pride,” or "Korean Pride.” This provides the other layer of the messagethe demonstration of pride in the youth's Khmer cultural heritage. This message is one that is also meant to distinguish their difference from other Asian youth-to mark a distance from other Asian youth. This is often in response to receiving derogatory comments from other youth in their communities such as: "You Chinese should go home."

Thus the textual productions centered on the words "Khmer Pride" are multilayered. They serve as a way for these youth to form themselves in collective terms - to mark a collective Khmer identity representing shared cultural, linguistic and historical experiences. This connects them to the larger Cambodian community in the greater Philadelphia area. These productions also serve as an important response or resistance to social situations the youth have experienced in their schools and in their communities. Hence, through these multimodal practices there is a mediation of the self, and of the collective self within these Khmer youth's urban contexts.

\section{Conclusions and Implications}

According to Suarez-Orozco \& Suarez- Orozco (2001), community based organizations geared to immigrant youth's experiences and interests can make a tremendous difference in their lives. This article shares a small glimpse into a migrant education program which centered on the cultures, experiences, and interests of its students across a range of activities and learning experiences. I have highlighted a wide range of the cultural productions the youth engage in as part of the Migrant Education Program to show the complexities of their nascent Khmer American identities. As demonstrated through the examples in this article, these semiotic productions offer youth non-traditional spaces for the creative production of the self. These Khmer youth were allowed to draw upon a variety of forms and modes to enact socially situated identities.

Through the "reorchestration" of the cultural resources they have available within the Migrant Education Program, these youth were (re)presenting and negotiating their identities of Khmer youth living in an urban context. As revealed in the data, a significant piece of this (re)presentation is the marking of collective identities - as Khmer youth, as urban youth, and as youth participating in the fast changing global culture. Through the reshaping of cultural forms, they are in the position and process of "reorchestrating" their individual selves, as well as their collective group identities.

The identity work of the Khmer youth is not static; rather, it is a process of identification, a process which includes shifting identities across social and cultural contexts. This process of identification is not free from tensions, constraints, or oppositions. Embedded within the youth's productions of their selves are the youth's responses to their social realities as Khmer living in an urban context. The identities of the Khmer youth are constituted in terms of the violence and poverty within their neighborhoods, in terms of similarity and difference to others, and in terms of 
generational distinctions. That is, these identities are socially constructed through the ways they are situated and positioned in relation to others, as well as how others interpret their expressions of their identities. For example, how they are positioned within schools as "at-risk" youth, or as "burdens.” Also, as Khmer immigrant youth they have limited access to resources that enable them to construct particular identities (Jenkins, 1996). Thus, the Khmer youth's multimodal expressions and cultural productions are embedded in ideologies.

While these cultural productions reflect the Khmer youth's multilayered identities in this particular place and at a particular time, they also represent their trajectories of future possibilities. As we saw with Prussia's video game character, he is imagining himself as one day being a video game maker. Thus, the choices and spaces afforded to youth within the Migrant Education Program can impact their abilities to create future possibilities and imaginings of future selves. Such productions can enhance the life chances and opportunities of these Khmer youth.

In addition, within these complex intricate cultural productions, the Khmer youth are taking a transformative stance to existing semiotic forms and creating their own productions. Through the recasting of forms, they are forging new multimodal expressions. Examples include, Prussia's video game character, Vantha's dragon, and the boy's martial arts performances. Thus, the Khmer youth are creating new cultural forms that carry culturally and socially significant meaning for them. That is, the Khmer youth's multimodal expressions are not only sites of identity work, but also of cultural innovation. Therefore, the Migrant Education Program provides an important space for cultural innovation.

In conclusion, this article raises awareness of how immigrant youth, like the Khmer youth in this study, use multimodal semiotic productions as expressions of their identities. Examinations of these productions can lead to deeper understandings of youth's complex processes of being and becoming, and draw attention to the deeper meanings communicated by youth through a range of modes about the realities of living in an urban American context. It points to the need for schools to move beyond models that approach immigrant youth from the nativist/assimilationist dyad to reveal how youth are in a position of (re)inventing their identities based on dynamic interaction between their own cultural values and symbols, and the cultural values and symbols of others. They are constructing complex identities "horizontally" within communities and contexts, and "vertically" through the transmission of values from one generation to another (Lowe, 1998). Finally, for educators or others who work with urban youth, this article points to the need to critically examine the ways immigrant youth are positioned in relation to others in our society, and to provide support, time and space for youth in expressions of self representation, through a range of modes.

\section{Acknowledgements}

I am grateful to the Khmer youth who shared their experiences with me. I would also like to thank Karen Clark, Jason Klugman, and Jackie Jackson for their thoughtful insights and suggestions regarding earlier drafts of this manuscript. I am also indebted to Dr. 
McGinnis: "Khmer Pride": Being and Becoming Khmer-American in an Urban Migr

McGinnis - “Khmer Pride:” Being and Becoming Khmer American

Nancy Hornberger for her meticulous feedback on my research. Finally I would like to thank Jeffery Gottesman for his support and editing advice.

\section{Endnotes}

1997.

${ }^{1}$ The film Lenora was produced by The Big Picture Alliance, Philadelphia, PA,

${ }^{2}$ Pseudonyms have been used for the participants to ensure anonymity.

\section{References}

Bakhtin, M. M., (1981). The dialogic imagination. Austin: University of Texas Press.

Barton, D., (1994). Literacy: An introduction to the ecology of written language. Oxford, UK: Blackwell.

Barton, D., \& Hamilton, M., (1998). Local literacies: Reading and writing in one community. London: Routledge.

Catlin, A., (1990). From Angkor to America: The Cambodian dance and music project of Van Nuys, California. Van Nuys, CA: Apsara Media for International Education.

Chan, S., (2004), Survivors: Cambodian refugees in the United States. Chicago: University of Illinois Press.

Collier, V. P., (1995). Promoting academic success for all ESL students. Woodside, NY: Bastos Educational Publishers.

Diaz, E. \& Flores, B., (2001). Teacher as sociocultural, sociohistorical mediator:

Teaching to the potential. In M. de la Luz Reyes \& J. Halcon (Eds.), The best for our children: Critical perspectives on literacy for Latino students (pp. 13-28).

New York City: Teachers College Press.

Gee, J., (1990). Social linguistics and literacies: Ideology in discourse. London: The Falmer Press.

Gee, J., (1999) An Introduction to discourse analysis: Theory and method. New York: Routledge.

Hall, S., (1997). Old and new identities, old and new ethnicities. In A. King (Ed.), Culture, globalization and the world system: Contemporary conditions for the representation of identity (pp. 41-69). Minneapolis: University of Minnesota Press.

Heath, S. B., (1983). Ways with words. Language, life and work in communities and classrooms. New York: Cambridge University Press.

Hein, J., (2006). Ethnic origins: The adaptation of Cambodian and Hmong refugees in four American cities. New York: Russell Sage Foundation.

Holland, D., Lachicotte, W., Skinner, D., \& Cain, C., (1998) Identity and agency in cultural worlds. Cambridge, MA: Harvard University Press.

Hodge, R. \& Kress, G., (1988). Social semiotics. Ithaca, NY: Cornell University Press.

Igoa, C., (1995). The inner world of the immigrant child. Mahwah, NJ: Lawrence Erlbaum Associates.

Jenkins, R., (1996). Social identities. London: Routledge.

Kiang, P., (1996). Persistence stories and survival strategies of Cambodian Americans in college. Journal of Narrative and Life History, 6(1), 39-64. 
Kress, G., (1997). Before writing: Rethinking the paths to literacy. London: Routledge.

Kress, G., (2000). Design and transformation: New theories of meaning. In B. Cope \& M. Kalantzis (Eds.), Multiliteracies: Literacy learning and the design of social futures (pp. 153-161). London: Routledge.

Ledgerwood, J., (1990). Changing Khmer conceptions of gender: Women, stories, and the social order. (Doctoral Dissertation, Department of Anthropology and the Southeast Asia Program. Cornell University, 1990). Dissertation Abstracts International, 51, 01.

Ledgerwood, J., Ebihara, M. \& Mortland, C., (1994). Introduction. In M. Ebihara, C. Mortland, \& J. Ledgerwood (Eds.), Cambodian culture since 1975: Homeland and exile, (pp. 1-26). Ithaca, NY: Cornell University Press.

Lee, S., (2005). Up against whiteness: Race, school, and immigrant youth. New York: Teachers College Press.

Levitt, P., \& Waters, M. C., (2002). Introduction. In P. Levitt \& M.C. Waters (Eds.), The changing face of home: The transnational lives of the second generation (pp. 132). New York: Russell Sage Foundation.

Lowe, L., (1998). Immigrant acts. On Asian American cultural practices. London: Taylor and Francis.

Marshall, C., \& Rossman, G. B., (1995). Designing qualitative research. Thousand Oaks, CA: Sage.

Martin-Jones, M., \& Jones, K., (2000). Introduction. In M. Martin-Jones \& K. Jones (Eds.), Multilingual literacies. Philadelphia: John Benjamins Publishing Company.

McCarthey, S., \& Moje, E. B., (2002). Identity matters. Reading Research Quarterly, $37(2), 228-238$.

McGinnis, T., (2005). “It means thank-you!” Culturally sensitive literacy pedagogy in a migrant education program. Afterschool Matters, 4, 10-16.

McGinnis, T., (2007). Are urban middle schools leaving bright immigrant youth behind? Voices from the Middle, 14(4), 32-38.

Needham, S. A., (1996). Literacy, learning and language ideology: Intracommunity variation in Khmer literacy instruction. (Doctoral Dissertation, Department of Anthropology, University of California, Los Angeles, 1996). Dissertation Abstracts International, 57(04), p. 1711.

Nieto, S., (1996). Affirming diversity: The sociopolitical context of multicultural education. New York: Longman.

Nou, L., (2006). A qualitative examination of the psychosocial adjustment of Khmer refugees in three Massachusetts communities. Journal of Southeast Asian American Education and Advancement, 1, 1-26. Available: http://jsaaea.coehd.utsa.edu/index.php/JSAAEA/article/viewFile/6/3

Ong, A., (2003). Buddha is hiding: Refugees, citizenship, and the new America. Berkeley, CA: University of California Press.

Perez, B., \& Nordlander, A., (2004). Making decisions about literacy instructional practices. In B. Perez (Ed.), Sociocultural contexts of language and literacy (pp. 277-308). Mahwah, NJ: Lawrence Erlbaum Associates.

Sam, S. A., (1994). Khmer traditional music today. In M. Ebihara, C. Mortland, \& J. 
McGinnis: "Khmer Pride": Being and Becoming Khmer-American in an Urban Migr

McGinnis - “Khmer Pride:” Being and Becoming Khmer American

Ledgerwood (Eds.), Cambodian culture since 1975: Homeland and exile (pp. 3948.). Ithaca, NY: Cornell University Press.

Smith, F., (1994). Cultural consumption: Cambodian peasant refugees and television in the "First World.” In M. Ebihara, C. Mortland, \& J. Ledgerwood (Eds.), Cambodian culture since 1975: Homeland and exile (pp. 1-26.) Ithaca, NY: Cornell University Press.

Smith-Hefner, N., (1999). Khmer American: Identity and moral education in a diasporic community. Berkeley, CA: University of California Press.

Street, B., (1995). Introduction. In B. Street (Ed.), Cross-cultural approaches to literacy. Cambridge, UK: Cambridge University Press.

Street, B., (2000). Literacy events and literacy practices: Theory and practice in the New Literacy Studies. In M. Martin-Jones \& K. Jones (Eds.), Multilingual literacies (pp. 17-31). Philadelphia: John Benjamins Publishing Company.

Suarez-Orozco, C., \& Qin-Hillard, D., (2004). Globalization. In M. Suarez-Orozco \& D. Qin-Hillard (Eds.), Globalization, culture and education in the new millennium (pp. 1-37). Berkeley: University of California Press.

Suarez-Orozco, C., \& Suarez-Orozco, M., (2001). Children of immigrants. Cambridge, MA: Harvard University Press.

Valenzuela, A., (1999). Subtractive schooling: U.S.-Mexican youth and the politics of caring. Albany, NY: State University of New York Press.

\section{About the Author}

Theresa McGinnis is an assistant professor in the Literacy Studies Department at Hofstra University. She earned her doctorate at the University of Pennsylvania in Reading, Writing and Literacy. Her dissertation, Khmer Youth in a Migrant Education Program: Discourses, Literacies and Possible Selves, describes the literacy and discourse practices of Khmer children of migratory farm workers as they engage with their urban schools and communities. Her teaching and research interests include sociocultural theories of literacy and discourses, the ways youth integrate reading and writing with other semiotic modes, and the culturally and socially significant meanings youth convey through their literacy and expressive practices. 


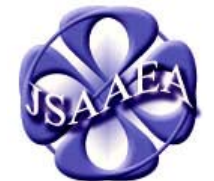

Volume 2

\section{Journal of Southeast Asian American Education \& Advancement WWw.JSAAEA.org}

Editor

Dr. Wayne E. Wright

University of Texas, San Antonio

Associate Editors

Dr. Chhany Sak-Humphry

University of Hawaii

Dr. KimOanh Nguyen-Lam

California State University, Long Beach

Book Review Editor

Dr. Leslie Turpin

School for International Training

Creative Works Editor

Phouang Hamilton

Washington Office of Superintendent of Public Instruction

Special Advisor

Anne Frank

University of California, Irvine, Southeast Asian Archives

\author{
Editorial Assistant \\ Shereen Bhalla \\ University of Texas, San Antonio
}

A peer-reviewed

scholarly journal published by the

National Association

for the Education \&

Advancement of

Cambodian, Laotian,

and Vietnamese

Americans (NAFEA)

Comments and questions for the editorial staff may be directed to jsaaea@lists.sis.utsa.edu

\section{Editorial Review Board}

Dr. Carl L. Bankston III

Tulane University

Dr. Pollie Bith-Melander

San Jose State University

Dr. Phala Chea

Lowell Public Schools

Dr. George Chigas

University of Massachusetts, Lowell

Dr. Changming Duan

University of Missouri, Kansas City
Dr. Sophal Ear

Syracuse University

Dr. Nancy H. Hornberger

University of Pennsylvania

Dr. Samlong Inthaly

Minneapolis Public Schools

Dr. Peter Nien-Chu Kiang

University of Massachusetts, Boston

Dr. Kevin K. Kumashiro

University of Illinois, Chicago 
McGinnis: "Khmer Pride": Being and Becoming Khmer-American in an Urban Migr

\author{
Dr. Stacey Lee \\ University of Wisconsin, Madison \\ Dr. David Chanpannha Ley \\ Montgomery County Public Schools \\ Dr. Sue Needham \\ California State University, Dominguez Hills \\ Dr. Bic Ngo \\ University of Wisconsin-Madison \\ Dr. Max Niedzwiecki \\ Rights Working Group \\ Dr. Leakhena Nou \\ California State University, Long Beach \\ Dr. Clara Park \\ California State University, Northridge \\ Dr. Mark Pfeifer \\ Texas A\&M University, Corpus Christi \\ Dr. Loan T. Phan \\ University of New Hampshire \\ Dr. Bounlieng Phommasouvanh \\ Minnesota Department of Education \\ Dr. Karen Quintiliani \\ California State University, Long Beach
}

\author{
Dr. Kalyani Rai \\ University of Wisconsin, Milwaukee \\ Dr. Fay Shin \\ California State University, Long Beach \\ Dr. Nancy J. Smith-Hefner \\ Boston University \\ Dr. Yer J. Thao \\ Portland State University \\ Dr. Myluong Tran \\ San Diego State University \\ Dr. Khatharya Um \\ University of California, Berkeley \\ Dr. Linda Trinh Vo \\ University of California, Irvine \\ Dr. Terrence G. Wiley \\ Arizona State University \\ Dr. Zha Blong Xiong \\ University of Minnesota \\ Dr. Kou Yang \\ California State University, Stanislaus
}

\title{
Doctoral Student \\ Editorial Review Board
}

\author{
Keo Chea \\ University of Pennsylvania \\ Vichet Chhuon \\ University of California, Santa Barbara \\ Loan Dao \\ University of California, Berkeley \\ Annie BichLoan Duong \\ San Joaquin County Office of Education \\ Ha Lam \\ Arizona State University \\ Vanna Som \\ Harvard University
}

\author{
Giang Tang \\ University of Minnesota \\ Layheng Ting \\ State University of New York, Albany \\ Loan Tran \\ University of California, Santa Barbara \\ Phitsamay Sychitkokhong Uy \\ Harvard University \\ Yang Sao Xiong \\ University of California, Los Angeles
}

